Comentários 



\section{Contando o que se canta}

\section{CARLOS RODRIGUES BRANDÃO ${ }^{I}$}

\section{A propósito de um livro de um professor violeiro}

$\mathrm{E}$ NTRE NÓs, possivelmente o último "homem dos sete instrumentos" terá sido Mário de Andrade. Outros terão existido e existem ainda, de menos instrumentos e talvez não tão fecundamente "afinados". Na realidade, na estrada de mão dupla que estaremos percorrendo aqui, tanto a que vai das ciências para as artes quanto a que volta das artes às ciências, poucos são os que "tocam" sequer dois instrumentos. "Tocam" e dão a ver o que tocam.

No entanto, sabemos que "de um lado e do outro" - nas artes, entre as artes, nas ciências, entre as ciências, entre as artes e as ciências, entre as ciências e as artes -, sobrevivem do passado remoto até hoje, em nós e entre nós, certas linguagens, certas formas-de-dizer, certos desejos de criar, que uma vez ou outra se encontram e entrecruzam em uma mesma pessoa. Raras, no entanto, as pessoas-criadoras em que dois modos de viver uma mesma arte ou, mais ainda, dois modos diversos de dizer, como o da arte-que-se-escreve e o da ciência-que-se-inscreve, realizam-se com um mesmo grau de acabamento, de perfeição, de plenitude.

Faz bastante tempo Rubem Alves presenteou-me com um velho disco de vinil. Um disco com música para piano e orquestral de Nietzsche. Ele me deu o disco dizendo: "foi um grande filósofo, mas nunca devia ter pensado escrever música". Ouvi o disco uma vez e concordei com ele. Richard Wagner escreveu uma pequena biografia de Beethoven. Melhor que tivesse pensado em criar uma breve cantata em seu louvor.

Apenas raros especialistas e estudantes leem ainda os trabalhos de Manuel Bandeira sobre literatura brasileira. Mas a sua poesia permanece viva e presente. João Cabral de Mello Neto escreveu e publicou alguns escritos de crítica literária e apreciação da arte. Quem os conhece? Cecília Meireles escreveu ensaios sobre folclore brasileiro. Eles são quase desconhecidos. E somente agora alguns estudos sobre a educação, escritos por uma mulher poeta que foi também uma professora, estão sendo editados.

Mesmo no interior da literatura, sabemos que a poesia de Carlos Drummond de Andrade reedita livros e reacende o desejo de leitura entre gerações que se sucedem. Mas acontece o mesmo com as suas crônicas? Em direção oposta João Guimarães Rosa escreveu poemas que nunca publicou. Depois de "encantado" os seus herdeiros publicaram Magma, seu único e oculto livro de poesia. Melhor que não houvessem feito o que ele mesmo nunca quis fazer. Há mais poesia em uma única página do Grande sertão: veredas do que em todo o seu livro de poemas. 
Entre os cientistas sociais e outros habitantes vizinhos do "mundo acadêmico" há vários (ou pelo menos alguns) autores a quem a aventura de uma outra linguagem acaba se realizando em uma inevitável via de mão dupla. Quantos volumes haveria de ter uma coletânea quase completa de romances, novelas, contos e poemas escritos por professores e cientistas da USP, da Unesp e da Unicamp, zelosamente escondidos, ou ocasionalmente circulantes apenas entre um pequeno e seleto grupo de amigos-confidentes?

Algumas exceções de um passado próximo ou do presente devem ser lembradas, no entanto. Até porque os seus autores-de-dupla-mão, depois de se haverem consagrado na "ida" (a viagem da ciência) ousaram se fazer editar na "volta" (a viagem de uma outra arte). Darcy Ribeiro passou da etnografia ao romance. Boaventura de Souza Santos publicou um livro de poemas. E José de Souza Martins retorna aos lugares que criteriosamente conheceu como cientista social (e em um caso, antes como "moleque-de-fábrica") e os revista criativamente como um fotógrafo. Como um artista da imagem, na verdade. E agora ele nos dá a ler dois livros de memórias que podem ser "viajados", ao mesmo tempo, como efetiva ciência confidente e como uma afetiva arte da lembrança.

Seriam eles e outros - e outras - capazes de assinar embaixo (com correções ou sem elas) desta passagem de Roland Barthes, quando ao ser empossado na cadeira de Semiologia Literária do Colégio de França, ele fez de sua "aula magna" uma "aula", e em um dado momento escreveu esta passagem que não resisto a transcrever aqui? Até porque, por uma fortuita coincidência, li Cantando a própria história nos mesmos dias em que relia Aula.

Se, por não sei que excesso de socialismo ou de barbárie, todas as nossas disciplinas devessem ser expulsas do ensino, exceto uma, é a disciplina literária que devia ser salva, pois todas as ciências estão presentes no monumento literário. É neste sentido que se pode dizer que a literatura, quaisquer que sejam as escolas em nome das quais ela se declara, é absolutamente, categoricamente realista: ela é a realidade, isto é, o próprio fulgor do real.

$[\ldots]$

A ciência é grosseira, a vida é sutil, e é para corrigir essa distância que a literatura nos importa. Por outro lado, o saber que ela mobiliza nunca é inteiro nem derradeiro; a literatura não diz que sabe alguma coisa, mas que sabe de alguma coisa; ou melhor, que ela sabe algo das coisas - que sabe muito sobre os homens. (Barthes, 2013, p.18 e 19)

Até onde sei, desde o passado remoto ou próximo, entre grande música renascentista, barroca, clássica e romântica, músicos escreviam música. Escreviam, aqui e ali, tratados de musicalização. Lembrei aqui o esboço biográfico de Beethoven escrito por Wagner. Mas desconheço ensaios teóricos ou "histórias da música" escritas por músicos. Se saltarmos de Beethoven a Milton Nascimento, aqui no Brasil, entre os nossos músicos "eruditos" e/ou "populares", raros os que escreveram sobre a música, além de escreverem música. Dois exemplos. Caetano Veloso escreve sobre suas peripécias como músico, escreve sobre a mú- 
sica de seu tempo e escreve a respeito dos pesares da indústria fonográfica, em Verdade tropical. Como Darcy Ribeiro na "ida”, Chico Buarque de Holanda esperou haver-se tornado um músico consagrado, e deixou Adélia Bezerra de Menezes teorizar sobre a letra de suas músicas, para então começar a escrever os seus livros de literatura.

E assim chegamos aos sertões do Brasil, ao "mundo da Roça”, aos caipiras, aos sertanejos, aos camponeses e às suas músicas. E assim chegamos a Ivan Vilela e ao seu livro: Cantando a própria história (Edusp, 2013).

Ora, no sinuoso intervalo que vai das "músicas do folclore brasileiro" registradas e estudadas por Mário de Andrade, às modernas variações de uma antecedente "música sertaneja", sempre foram muito raros os momentos em que algum "tocador de viola e cantador de pagode ou moda e viola" tenha escrito algo mais do que as letras e (raro) notações musicais de suas composições.

Em uma breve trajetória que vai dos primeiros folcloristas aos estudiosos especialistas de "música brasileira" e, deles, a antropólogos e outros cientistas sociais, desde um passado bem próximo até quase agora, tudo o que se escrevia a respeito da história ou do momento presente de alguma modalidade de música, do "partido alto" dos morros cariocas aos "recortados de catira" dos fundos de Goiás, passou de estudiosos vindos das artes, como Cornélio Pires e Mário de Andrade, a pessoas da vizinhança ou da intimidade da academia. Ivan Vilela lembra Oneyda Alvarenga, Cornélio Pires, Amadeu Amaral, Waldenyr Caldas, e lembra também Alfredo Bosi, Antonio Candido, Florestan Fernandes e José de Souza Martins. Diferentes vocações e estilos de abordagem não apenas de música, mas de contextos e momentos culturais em que elas foram geradas, enraizadas, transformadas, desenraizadas e, esperemos, reenraizadas.

Ora, por razões e variações que entre a "ida" e a "volta", vão das artes para as ciências e das ciências para as artes, em um mundo universitário em que um físico teórico não precisa saber tocar violino para ser um doutor, um violeiro precisa escrever um trabalho dentro dos recortes (mas não dos "recortados") que a ciência acadêmica impõe a físicos, filósofos e artistas, para alguém se fazer um doutor. Foi o que fez Ivan Vilela.

E penso que devo começar a falar a respeito de Cantando a própria história estendendo a quem me leia um trecho da caipira dedicatória com que generosamente o autor me ofertou um exemplar do livro: “Êh, Capitão Barandão, toda a marcha é dobrada...”.

E a caipira palavra “dobrada” aqui se aplica em um também duplo sentido.

"Dobrada" quer lembrar que todo o caminhar pela vida é um viajar por uma quase sempre longa, difícil e dura estrada. Nunca conheci um homem do campo que me dissesse que sua vida foi fácil e não foi "vencida" à custa de trabalho, paciente persistência e sofrimento. Mas o segundo sentido é aqui aquele que mais nos interessa. "Dobrada" pode significar que no andar pela vida, algumas pessoas enfrentam a experiência de se virem convocadas a se repartir 
entre duas ou mesmo mais de duas "sinas" ou vocações. "Sina", ou "destino" - mas jamais "vocação", termo urbano e erudito demais - serão palavras que um camponês lavrador, violeiro e folião de Santos Reis, usará para explicar por que, à diferença de "quase toda a gente por aqui", ele "desde menino" teve que aprender a passar do cabo da enxada para o braço da viola. Ou por quais motivos uma rude voz que deveria limitar-se à breve fala da gente do campo e ao aboio do gado (prática em extinção) educou-se também para se tornar uma apreciável "segunda voz" em uma "dupla caipira", ou mesmo uma aguda "requinta", nos cantos devotos da Folia de Santos Reis.

Ora, para compreendermos o modo como Ivan Vilela escreveu o seu livro, é necessário conhecer algo do "outro lado" dele. Em termos de vida e trabalho propriamente universitário não seria um exagero dizer que Ivan Vilela é um quase jovem estreante na vida em que um professor de sala de aulas se alterna com o pesquisador de documentos e/ou de campo (em seu caso, no duplo sentido da palavra "campo").

Este é o seu primeiro livro, mas não o seu primeiro escrito sobre os temas de Cantando a própria história. Ivan já publicou alguns artigos relevantes em revistas. Na vertente ainda menos conhecida de sua vida, até onde sei, Ivan Vilela é o primeiro professor de viola caipira aqui no Brasil... e no mundo.

Mas na outra vertente ele é um virtuoso violeiro. E ao lado de jovens e outrora jovens de afortunadas gerações seguidas, Ivan Vilela resolveu deixar de lado outros instrumentos mais "sérios e afamados", como o próprio violão, e elegeu a nossa roceira e rústica "viola caipira" como o seu instrumento único.

Nada mais acertado. E assim Ivan Vilela participou do surgimento e participa agora da consolidação de um dos acontecimentos mais importantes (e pouco conhecidos) na história da música deste país. Falo da redescoberta, da reinvenção e de um verdadeiro renascimento da viola caipira no Brasil. Fora o virtuosismo com que Ivan Vilela cria e executa as suas músicas com uma viola caipira, devemos a ele o ser um dos assumidos "herdeiros de Renato Andrade". Herdeiros, também, de Tião Carreiro e Pardinho. Jovens, homens e mulheres, a quem ficamos devendo um verdadeiro movimento de reenraizamento da viola no Brasil.

E quero enfatizar aqui esta palavra: "enraizamento", essencial em seu livro - não fosse ele orientado por Ecléa Bosi. De um lado essa palavra é aquela que nos chega em linha direta de Simone Weil, e que Ivan transporta para o chão de seu livro. Pois em sua parte mais essencial, é de nascimentos, enraizamentos, perdas, desenraizamentos e a esperança de novos e outros enraizamentos que se trata.

Sobretudo quando o que se narra e descreve são os caminhos e descaminhos de uma forma múltipla de música que, nascida nos ermos dos redutos camponeses, vê-se obrigada a migrar com os seus herdeiros para a cidade. E ali, para não se perder, ela se reinventa, se recria, relança no asfalto as mesmas e ou- 
tras raízes para produzir frutos que se dividem. Que de uma "fase" para outra de sua história repartem-se entre os que preservam o sabor e o valor dos primeiros tempos rurais, e aqueles em que algo como a "moda de viola" aos poucos cede lugar a músicas em que a palavra “sertanejo" vale mais como um apelido maldoso do que como um nome carinhosamente consagrado.

Um outro sentido de enraizamento é aquele em que Ivan Vilela, ao narrar a trajetória dos tempos ou das "fases" da música de que fala (e toca), realiza uma dupla intrigante (no sentido não caipira da palavra) dupla história. De um lado a história das estórias dos acontecimentos de vidas, violas e músicas de origem caipira, ao longo dos anos que vão da chegada da viola ao Brasil, com os primeiros colonizadores portugueses, até os dias de agora. E, em outra direção, a história que com uma hoje quase esquecida sabedoria, a própria letra da temática das músicas caipiras relata, entre toques e rimas. Músicas que vão de uma sentida moda de viola a um alegre e quase debochado pagode, e que, bem mais a fundo do que a nossa MPB, realizam uma realista (como em Barthes) e criativa crônica de estórias e histórias que vão de "Cabocla Teresa" a "O rei do gado", e dele a "No sertão do Laranjinha" e, dele, a várias antigas modas que versejam a própria Revolução Constitucionalista de 1932.

Talvez em parte pelo que possui de raízes fincadas nos romances ibéricos, a nossa música caipira é quase sempre uma longa e não raro talentosa narrativa de toda uma história, do começo ao fim. Se a conhecesse bem, Walter Benjamin dedicaria todo um longo artigo a ela. Ao contrário da musica da cidade, que mesmo quando épica é sempre resumidamente lírica, e apenas delineia - mesmo quando com a maestria de Chico Buarque - um breve acontecer, quando uma música caipira começa dizendo "vou contar a minha história..." quem a ouça pode esperar uma demorada narrativa que transforma mesmo um "caso lírico de amor" em uma pequena epopeia de muitos versos entre um estendido começo, um longo meio e, quase sempre, um “triste fim”.

Creio mesmo - e na mesma toada de Ivan Vilela - que a poesia de cordel e a moda de viola são duas das modalidades mais completas, criativas e sábias de narrativas que transitam sem problemas de um pequeno "causo de amor" local a questões cosmológicas sobre a possível existência de ET que visitam a Terra, e nos salvem de nós mesmos. Coisa que um samba-canção nunca ousou fazer.

Contando a própria história possui sete capítulos. O primeiro e o último aparentemente se opõem. Mas, mediados pelos outros cinco, eles apenas se completam.

O primeiro capítulo é uma rigorosa história-etnográfica da viola - melhor dizer: das violas - entre árabes, portugueses e os nossos caipiras do Centro-Sul e violeiros do Nordeste. Ou do Centro-Oeste, se pensarmos na não esquecida viola-de-cocho. Entre a história da viola e as estórias de violeiros - nas quais o próprio Diabo vai se apresentar como um ator essencial -, Ivan Vilela faz um generoso percurso entre a história documental e o mito. 


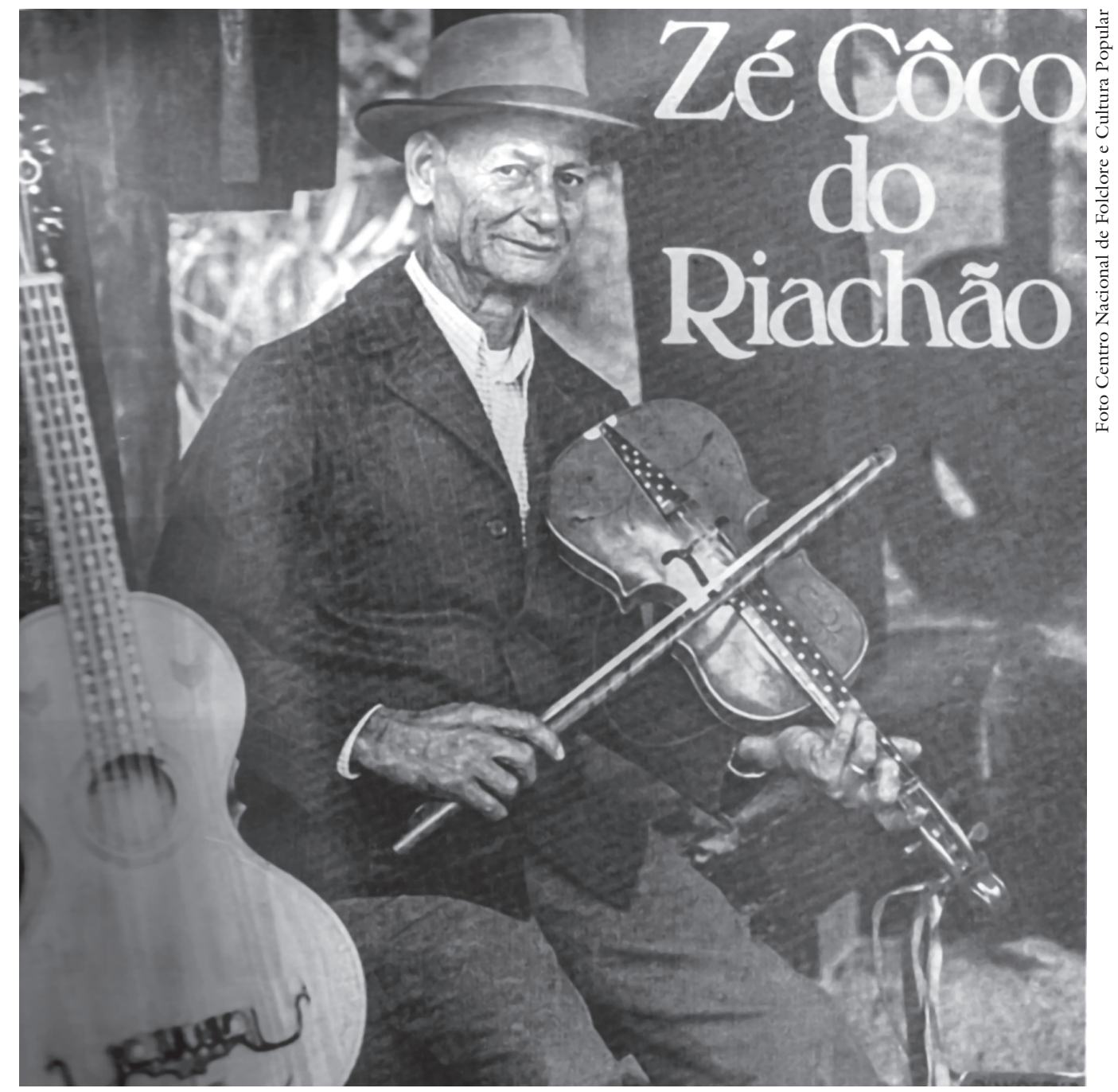

José dos Reis Barbosa dos Santos (1912-1998), um dos maiores nomes da música caipira.

O capítulo final devolve a história à memória, e demoradamente traz ao leitor uma série inapagável de depoimentos de pessoas, homens e mulheres, de vida enraizada entre a viola e o compor e cantar com a viola.

A meio caminho entre uma história que se narra e uma memória que se conta, Contando a própria história vai da viola à música que tradicionalmente se faz acompanhar da viola. Uma música que por anos, justamente por ser "caipira”, foi, como Ivan Vilela narra, "deixada pra lá". Deixada à margem e viva apenas nos cantos roceiros de um Brasil que eu mesmo percorri entre Goiás, Minas Gerais e São Paulo, ao longo de mais de cinquenta anos, na esteira de foliões de Santos Reis, de folgazões de São Gonçalo, de dançadores da Santa Cruz (ainda vivos na pequenina aldeia de Carapicuíba?). Eles e tantos outros, uma gente de viola, caixa, pandeiro e voz, entre cantos e festas dedicados a santos padroeiros ou a momentos de pura e roceira "diversão", aquilo que "na roça" em geral, nas festas e nas rezas aos santos, vem em seguida à "devoção". 

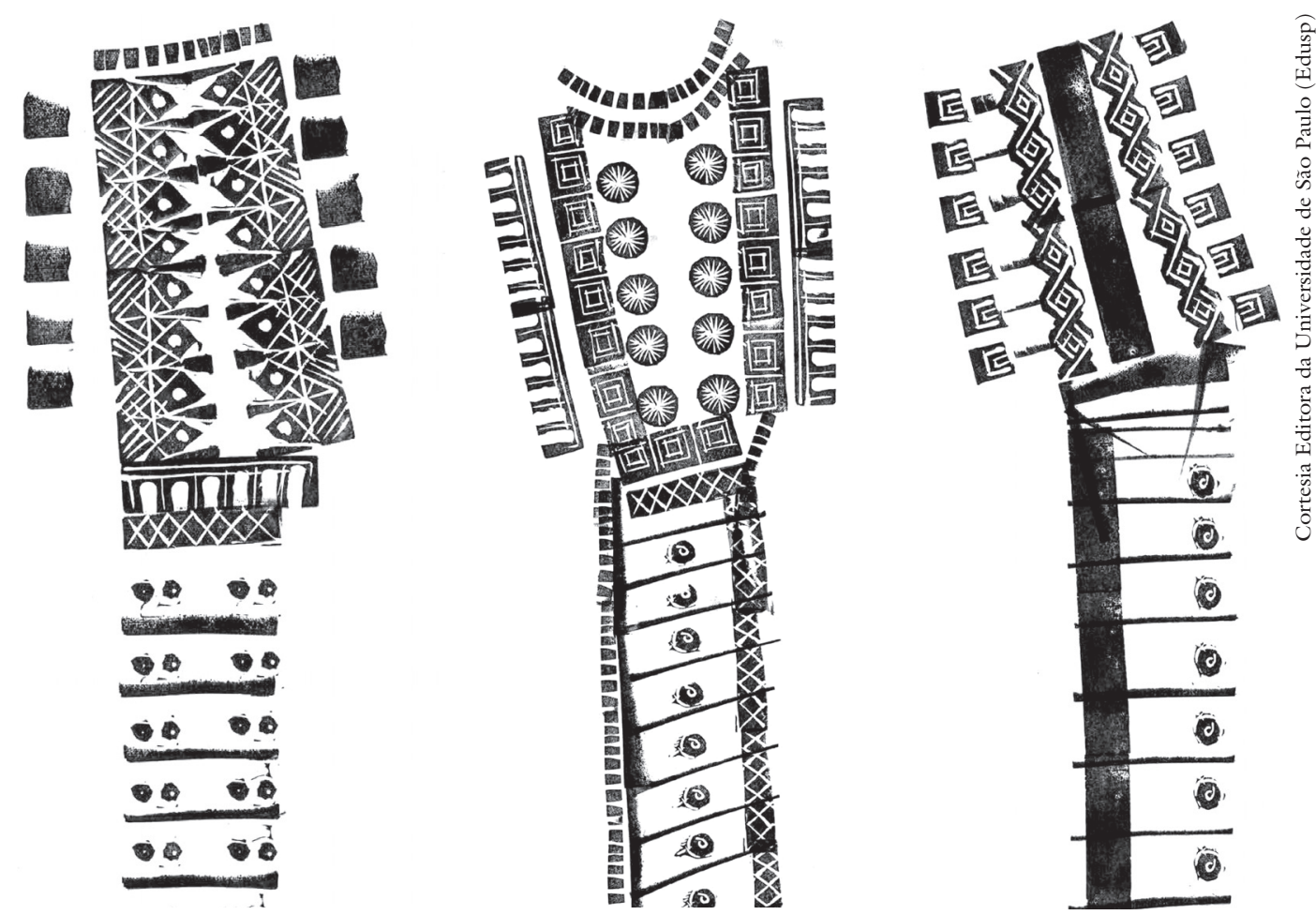

Ilustrações de violas caipiras de Fernando Vilela.

Devo relembrar, o aporte mais "afinado" deste livro, ao longo dos capítulos dedicados à história de mão dupla da música caipira, está na maneira como Ivan Vilela nos traz o arcabouço das ideias gestadas por Simone Weil - e enraizadas entre nós através da semeadura de Ecléa Bosi - a partir do próprio "enraizamento", e de seus caminhos e descaminhos.

Mesmo tocando em algum teatro em Barcelona, Ivan Vilela nunca esquece que é de Itajubá. Este seu primeiro livro traz para a escrita no papel uma das qualidades com que, em sua outra "via", Ivan dedilha a viola: uma arguta sensibilidade para tratar de raízes e perdas que vão de um instrumento que se toca ao que se cria e canta com ele. E que vão da música que se canta à memória viva de quem, cantando-a, conta a sua própria história.

Certa feita, quando Os deuses de Itapira, minha distante tese de doutorado defendida na USP e orientada primeiro por Douglas Teixeira Monteiro e, depois, por José de Souza Martins, foi publicada como livro, com este nome: $O s$ deuses do povo, Martins ousou começar o seu generoso prefácio com esta afirmação: "Carlos Rodrigues Brandão é um caipira legítimo nascido em Copacabana, Rio de Janeiro" (Brandão, 2007, p.15). Anos mais tarde, e com mais razões, gostaria de estender esse virtuoso qualificador - "caipira" - a um sul-mineiro.

Porque essa é a sua mais rústica e enraizada virtude: tanto no que escreve quanto no que compõe e toca na viola, ser capaz de alçar voos de uma corajosa e audaz criatividade. Mas voar alto, sem nunca se afastar das raízes que, de tão enraizadas nele, permitem justamente isso, os altos voos do imaginar. 
Referências

BARTHES, R. Aula. São Paulo: Cultrix, 2013.

BRANDÃO, C. R. Os deuses do povo - um estudo sobre a religião popular. Uberlândia: Editora da Universidade Federal de Uberlândia, 2007.

VILELA, I. Cantando a própria história. São Paulo: Edusp, 2013.

Rosa dos Ventos, Caldas, Sul de Minas

Verão de 2014

Carlos Rodrigues Brandão é professor colaborador do Programa de Pós-Graduação em Antropologia da Universidade Estadual de Campinas (Unicamp) e professor visitante sênior da Universidade Federal de Uberlândia (UFU). @ - carlosdecaldas@gmail.com

Recebido em 17.02.2014 e aceito em 28.02.2014.

I Programa de Pós-Graduação em Antropologia, Universidade Estadual de Campinas. Campinas/SP, Brasil. 